\title{
SYNTHESIS OF TITANIUM (III) SULFATE BY ELECTROCHEMICAL METHOD
}

\author{
G.M. Iztleuov ${ }^{1, \bowtie}$, S.S. Bitursin”, , A.B. Baeshov ${ }^{3}$, A.E. Bitemirova ${ }^{2}$, K.Z. \\ Kerimbayeva $^{2}$, A.A. Abduova ${ }^{1}$ and A.Zh. Dairabaeva ${ }^{1}$ \\ ${ }^{1}$ M. Auezov South Kazakhstan University/ Department of Ecology Shymkent, Kazakhstan \\ ${ }^{2}$ Sokolsky Institute of Fuel, Catalysis and Electrochemistry, Almaty, Kazakhstan \\ ${ }^{3}$ South Kazakhstan Pedagogical State University/ Department of Chemistry, Shymkent, \\ Kazakhstan \\ ${ }^{\circledR}$ Corresponding Author: iztileuov.gani@bk.ru
}

\begin{abstract}
Electrochemical solution the first study was made of the behavior of titanium polarized by an alternating current of industrial frequency in a solution of sulfuric acid. Existing methods of synthesis of titanium compounds are characterized as energy-intensive and labor-intensive, which in turn negatively affects their cost. One of the most effective and affordable methods is electrochemical methods. In this article, the electrochemical dissolution of metallic titanium in a solution of sulfuric acid using a polarizing industrial alternating current is investigated. The review presents, depending on various factors: the density and frequency of the alternating current, the concentration of the electrolyte and the duration of the electrolysis, the current efficiency of titanium, and it was found that with increasing acid concentration, the chemical dissolution of titanium increases, so the apparent current yield of titanium dissolution is: $9 \mathrm{MH} 2 \mathrm{SO} 4-70 \%$. A new electrochemical method for obtaining the polarization of titanium sulfate by the alternating industrial current in an acidic medium has been developed.

Keywords:Titanium (III)sulfate, Electrolysis, Electrochemical Dissolution, Current Output.

RASĀYAN J. Chem., Vol. 14, No.4, 2021
\end{abstract}

\section{INTRODUCTION}

Titanium and titanium-based alloys combine various positive properties, such as low density, high stiffness, good corrosion- and creeping resistance, and biocompatibility. Titanium is widely used in aircraft and shipbuilding, chemical and metallurgical industries, in this regard, when processing metallic titanium, a large amount of waste of this metal is formed. The problem of processing and using titanium wastes is extremely urgent; great attention has been paid to solving this problem from the very beginning of the industrial production of titanium. The processing of these wastes is associated with great difficulties since titanium is hardly soluble, refractory $\left(\mathrm{t}_{\text {melt }}=1725^{\circ} \mathrm{C}\right)$ and hard metal. Titanium is corrosion resistant in acidic and alkaline solutions and dissolves only in concentrated sulfuric acid at its boiling point at a very low rate. In this regard, titanium waste was practically not processed. ${ }^{1-2}$

Metal waste generated during the processing of titanium products can be divided into two groups. Only the surface layer of the waste of the first group is contaminated metals. Waste of the second group, as a rule, refers to waste that is completely contaminated not only by the surface but also by volume. Since the last waste is difficult to recycle, special methods are used in production. Osamu takeda shows that titanium scraps such as swarf (or cutting chips, turnings) generated in the fabrication of titanium alloy parts, are collected and cleaned are then recycled by remelting in high temperature. ${ }^{3}$

Consideration of ways of processing titanium-containing solid waste allows increases not only the resources of this metal but also reduces the cost of products obtained from it. The last mention is very important for the precious metal - titanium. ${ }^{4,5}$

Some literature shows that $70-75 \%$ of waste is generated during the production of titanium products. Only $25-30 \%$ of the feedstock is used as the gross product. In production, only a remitting method of processing these wastes is used. But this method is not always effective since when oxidized titanium residues are 


\section{RASĀYAN J. Chem.}

melted on the surface at a very high temperature, a product of very poor quality is obtained as a result of repeated interaction with air. To improve this method, special structural furnaces should be processed without the participation of air. ${ }^{6-7}$

The oxide layer formed on the surface of titanium granules is not always stable, so phosphoric acid is used as a solvent. Dissolution of titanium granules in phosphoric acid at a temperature of $220-240{ }^{\circ} \mathrm{C}$, increases in a straight line over time. After dissolving the oxide layer on the surface of titanium residues, it is very difficult to extract oxygen directly from titanium metal with modern technology. Therefore, many studies on the removal of oxygen are carried out at an early stage, with the exception of a few industrial processes, the reduction of titanium residues with metallic calcium and electric purification of titanium sponge in molten salts. ${ }^{8-10}$

An expensive method is the electrorefining of titanium metal waste, in which, in the process, crude titanium metal dissolves anodically in molten salt at a high temperature in the form of titanium ions at the anode, and high-purity titanium dissolves at the anode. Deposited on the cathode in molten salts has been investigated by some scientists. ${ }^{10-11}$

One of the promising ways to solve this problem is the dissolution of titanium waste with the subsequent synthesis of its compounds, which are widely used in various branches of the light and chemical industries. However, the existing methods of obtaining titanium compounds have many disadvantages and are very expensive since the dissolution of the metal is carried out at high temperatures in concentrated acids for a long time. It is also known that titanium does not dissolve during anodic polarization due to the formation of oxide films on its surface. ${ }^{12-14}$

Titanium compounds are widely used in the field of chemistry and metallurgy. For example, trivalent titanium salts are used as reducing agents in chemical processes and as charge carriers in the reduction of hard-to-recover anions of selenium (VI), tellurium (VI), and arsenic (V), as well as in the preparation of ultrafine copper powders, as well as in leather processing. Existing methods of synthesizing titanium compounds are characterized as energy-consuming and labor-intensive, which negatively affects their cost. ${ }^{16-18}$ One of the most effective and affordable methods is electrochemical, but in this case, it also did not find application because these metals are passivated during anodic polarization by direct current. The most likely reason for the presence of titanium and other refractory metals in these media in the passive state is the formation of a protective oxide film on their surface that is not completely soluble in water, acids and alkaline solutions, which excludes direct contact between the electrolyte and the clean surface of the metal. $^{5-6}$ These films are formed on the metal surface in a matter of fractions of a second, and their composition varies depending on external conditions.

To date, a large number of works on the chemical corrosion of titanium have been accumulated. Thus, it was established that titanium is stable in solutions: $\mathrm{FeCl}_{3}$ concentrations up to $30 \%$ and up to $100{ }^{\circ} \mathrm{C}$, $\mathrm{CuCl}_{2}$-up to $20 \%$ and $100{ }^{\circ} \mathrm{C}$, - NaCI of all concentrations up to $100{ }^{\circ} \mathrm{C}$. in $100 \%$ chloroacetic acids. It is stable in sodium hypochlorite solutions up to $10^{\circ} \mathrm{C}$. The nature of the dependence of the rate of dissolution of titanium on the concentration of $\sim$ sulfuric acid is complex. There are two maximum dissolution rates at concentrations of $40 \%$ and $75 \%{ }^{7-8}$ But the rate of dissolution of titanium is very low. Thus, titanium can be used for the manufacture of devices, pumps and communications for working with these substances.

Thus, in the literature, the issues of chemical and electrochemical corrosion of titanium are widely covered, but there is practically no data on the electrochemical dissolution of titanium in order to obtain its inorganic compounds since, as noted above, anode passivity is an insurmountable barrier. ${ }^{13-14}$

Preliminary studies have shown that when $\mathrm{Ti}, \mathrm{Mo}$, and $\mathrm{W}$ are polarized by the alternating industrial current in aqueous solutions, their intensive dissolution with the formation of their inorganic compounds is observed. ${ }^{1-2}$ In this regard, conducting comprehensive studies of the dissolution of refractory metals under the action of alternating current using aqueous electrolytes is an urgent task, has practical and theoretical significance. Based on the results of these studies, it is possible to establish optimal conditions for the synthesis of refractory metal compounds and develop industrial technologies. Therefore, the study of the electrochemical dissolution of titanium waste in aqueous solutions during polarization by an unsteady current of an industrial frequency of $50 \mathrm{~Hz}$ in room temperature $20-22{ }^{\circ} \mathrm{C}$, followed by the synthesis of its compounds, is of great interest. Previously, we studied the electrochemical dissolution of titanium during polarization by industrial symmetric and asymmetric alternating current; it was shown that its trivalent ions 
are formed in aqueous solutions. In these works, it was found that after preliminary treatment of titanium chips with alternating current, their chemical dissolution is observed. In this regard, the purpose of the thesis is to study the electrochemical dissolution of titanium metal waste during polarization by a non-stationary industrial current and the synthesis of its compounds.

The purpose of this work was to study the effect of the duration of preliminary polarization with alternating current, as well as to create an electrochemical method for obtaining titanium (III) sulfate at room temperature $20-22{ }^{\circ} \mathrm{C}$.

\section{EXPERIMENTAL}

The research of electrochemical dissolution of titanium was carried out in an electrolytic cell. The electrolysis was carried out in a glass electrolyzer with two titanium electrodes with the same area in a solution of sulfuric acid. The current density on the electrodes varied widely. Preliminary electrolysis was carried out at direct current. The results showed that when a direct current is applied, one of the titanium electrodes that are the anode is covered with an oxide film, and the electrode is passivated, the current flow in the electrical circuit stops. During electrolysis of titanium electrodes by an alternating industrial current with a frequency of $50 \mathrm{~Hz}$, the solution in the near-electrode space was colored purple, which indicates the dissolution of the electrodes and the formation of trivalent titanium ions. After a certain time, crystals of salts of trivalent titanium ions begin to fall out (Fig.-1).

Titanium metals were used from the Ust-Kamenogorsk titanium-magnesium factory with a titanium content of at least $98 \%$ (Table-1).

Table-1: Chemical Composition of Titanium

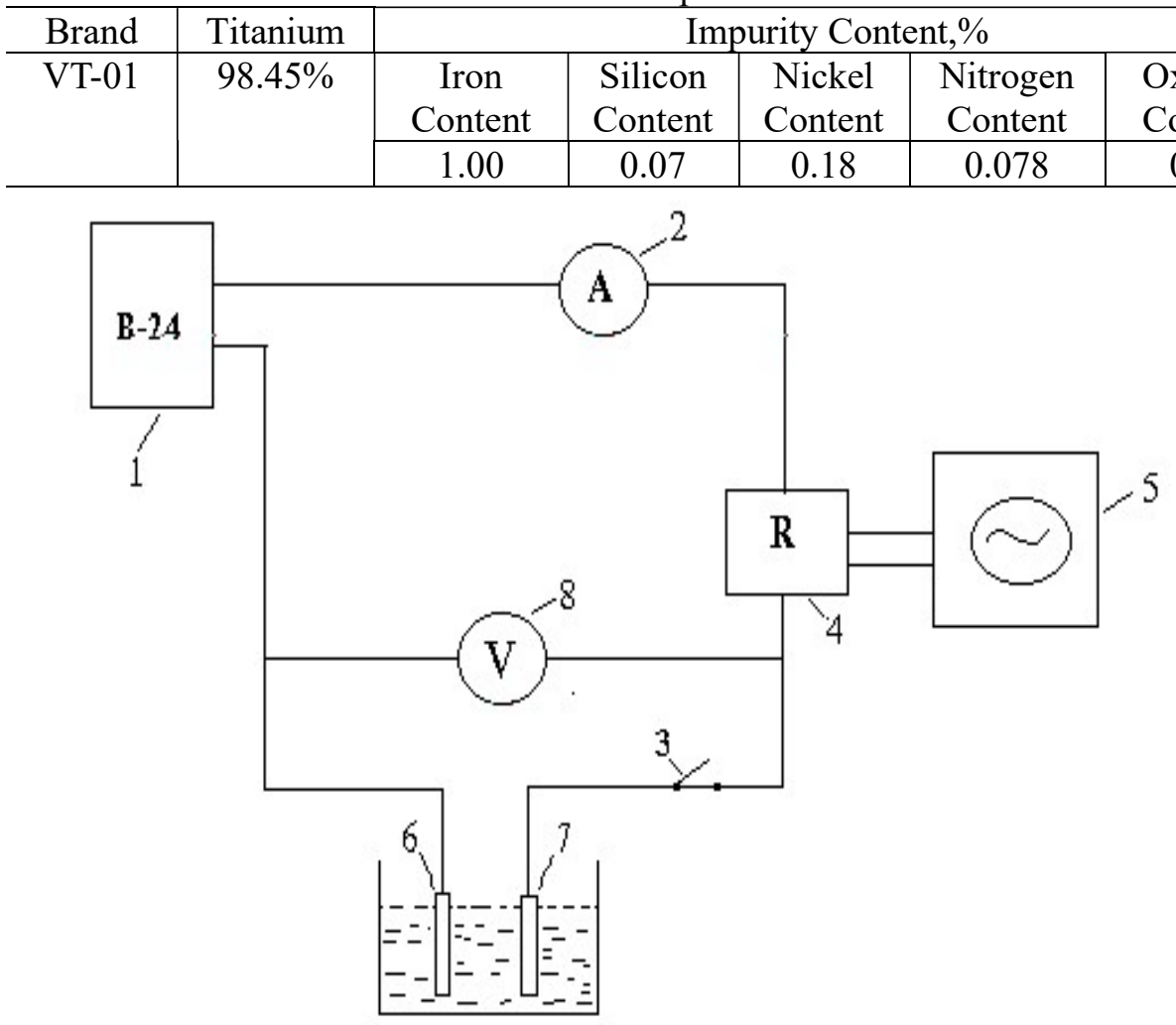

Fig.-1: Scheme of the Installation for Conducting Electrolysis with Titanium Electrode by Alternating Current

The degree of purity of all reagents used corresponds to the names "chemically clean" or "clean for analysis". All solutions were prepared with distilled water. Photocolorimetric method was used for the determine the concentration of titanium (IV) ions in an acidic solution..$^{2-3}$ This method is based on the interaction of these metal ions with dianthyrylmethane in an acidic environment. In a neutral medium, by dissolving the formed titanium (IV) hydroxide in acid, the amount of titanium in it was determined by photocolorimetric method. 
Current efficiency is defined as the ratio of the number of equivalents of a single electrode product to the total possible number of equivalents computed by Faraday's law of electrolysis. Deviations from Faraday's law are caused by simultaneous electrode reactions, by the interaction of anodic and cathodic products, by the diffusion of anodic and cathodic products from one electrode to another so that an electrolytic reversal of electrode processes ensues, and by the phenomena of mixed electrolytic and electronic conductance. It is well known that current efficiencies depend on the electrode material, the current density, and to a lesser extent on the concentration of the electrolyte and the temperature. It is necessary, therefore, to determine the current efficiency at several concentrations and obtain the current efficiency at a definite concentration by interpolation of the data. The current efficiency is calculated as the ratio of the mass of the actually reacted substance $\mathrm{mf}$ to the theoretical mass transfer mt, calculated according to the 1st Faraday law. Based on comprehensive studies of the electrochemical behavior of titanium under alternating current polarization in acidic solutions, we have developed a method for producing trivalent and tetravalent titanium sulfate.

\section{RESULTS AND DISCUSSION}

The electrolysis was carried out in a glass cell with two titanium electrodes with the same area in a solution of sulfuric acid. The current density on the electrodes varied widely. Preliminary electrolysis was carried out at direct current. The results showed that when a direct current is applied, one of the titanium electrodes, that is, the anode, is covered with an oxide film, and the electrode is passivated, the current flow in the electrical circuit stops. During the electrolysis of titanium electrodes by an alternating industrial current with a frequency of $50 \mathrm{~Hz}$, the solution in the near-electrode space was colored purple, which indicates the dissolution of the electrodes and the formation of trivalent titanium ions. After a certain time, crystals of salts of trivalent titanium ions begin to fall out.

The influence of the AC frequency on the current efficiency of titanium dissolution in sulfuric acid solutions is investigated. It is found that with an increase in the frequency of the alternating current, the current efficiency passes through the maximum at $50 \mathrm{~Hz}$ and is $69.3 \%$, i.e., at a current frequency of $50 \mathrm{~Hz}$, the optimal duration of the alternating current half-cycles is realized. Thus, during the heat treatment of the salt, it interacts with the oxygen of the air and polymerizes. The influence of the AC current density on the current efficiency of titanium dissolution with the formation of trivalent titanium sulfate is studied (Table2). As can be seen from the table, at current densities on titanium electrodes above $1000 \mathrm{~A} / \mathrm{m}$, " the current efficiency of their dissolution decreases linearly, which is associated with an increase in the share of side processes, and the dissolution rate initially increases, and then practically does not change. ${ }^{15}$

Table-2: Effect of the Current Density on Titanium Electrodes on Current Efficiency and Rate of Their Dissolution $(\mathrm{V})$, under Alternating Current Polarization $\mathrm{C}\left(\mathrm{H}_{2} \mathrm{SO}_{4}\right)=3 \mathrm{M} ; \mathrm{t}=20^{\circ} \mathrm{C} ; \mathrm{T}=0.5$ hour

\begin{tabular}{c|c|c|c|c|c}
\hline i. A $/ \mathrm{m}^{2}$ & 500 & 700 & 1000 & 1200 & 1500 \\
\hline$\Delta \mathrm{m}, \mathrm{g}$ & 0,0417 & 0,08415 & 0,10575 & 0,1029 & 0,06795 \\
\hline $\begin{array}{c}\text { Current efficiency, \% } \\
\begin{array}{c}\text { Rate of the dissolution } \\
\text { V,g/m }\end{array} \mathrm{M}^{2 *} \text { hours }\end{array}$ & 30,75 & 39,5 & 30,4 & 25,5 & 23,8 \\
\hline
\end{tabular}

With polarization with alternating current, titanium dissolution is observed, which makes it possible to obtain various titanium compounds by the electrochemical method. The main electrode process occurring in the cathodic half-period of an alternating current is the discharge of hydrogen ions and the restoration of the oxide film existing on the electrode surface

$$
\begin{aligned}
2 \mathrm{H}^{+}+2 \mathrm{e}^{-} & \rightarrow \uparrow \mathrm{H}_{2} \\
\mathrm{TiO}_{2}+4 \mathrm{H}^{+}+4 \mathrm{e}^{-} & \rightarrow \mathrm{Ti}+2 \mathrm{H}_{2} \mathrm{O} \quad \mathrm{E}^{0}=-0,90 \mathrm{~V}
\end{aligned}
$$

In the anodic half-period of alternating current, titanium is mainly dissolved in the form of trivalent ions:

$$
\mathrm{Ti}-3 \mathrm{e}^{-} \rightarrow \mathrm{Ti}^{3+} \quad \mathrm{E}^{0}=-1,21 \quad \mathrm{~V}
$$


RASĀYAN J. Chem.

Vol. 14 | No. 4 |2720-2727| October- December | 2021

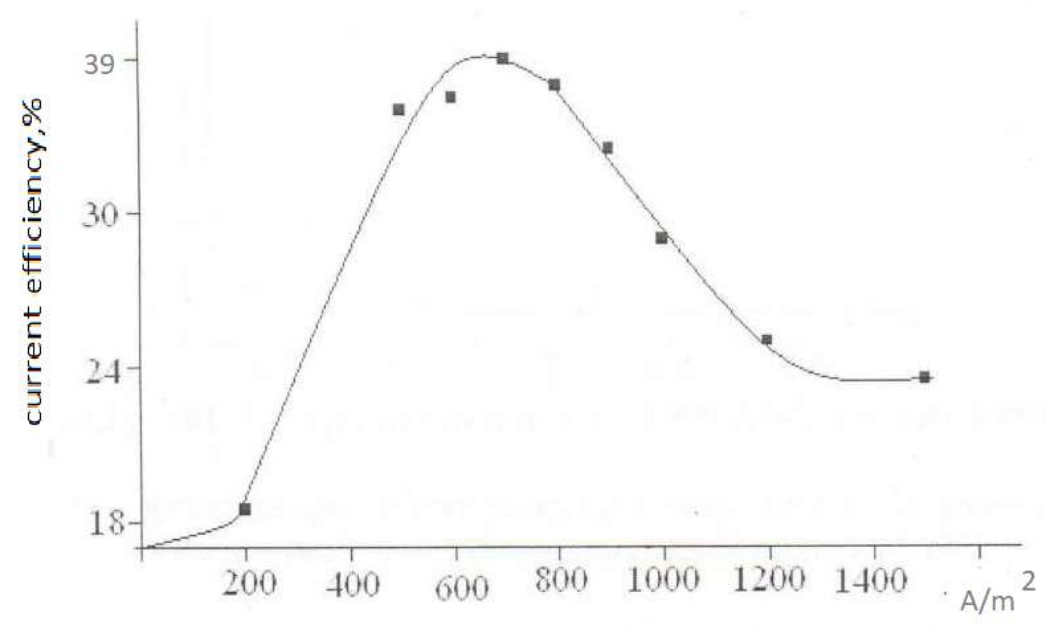

Fig.-2: Effect of the Current Density on Titanium Electrodes on Current Efficiency of Dissolution of TitaniumC

$$
\left(\mathrm{H}_{2} \mathrm{SO}_{4}\right)=3 \mathrm{M} ; \mathrm{t}=20^{\circ} \mathrm{C} ; \mathrm{T}=0.5 \text { Hour }
$$

Further, the mechanism of titanium dissolution in sulfuric acid solutions under industrial alternating current polarization is investigated. It is established that the dissolution of titanium occurs in the anode half-cycle of alternating current with the formation of salts of trivalent titanium sulfate. The efficiency of the process is reduced due to the side process of oxygen release, which leads to an increase in the thickness of the oxide film and, as a result, the voltage at the electrode increases.

$$
\mathrm{Ti}+\mathrm{H}_{2} \mathrm{O} \rightarrow \mathrm{TiO}^{2+}+2 \mathrm{H}^{+}+4 \mathrm{e} \quad \mathrm{E}^{0}=-0,88 \mathrm{~V}
$$

In the cathode half-cycle of alternating current, hydrogen is released, and the passivation of the electrode surface is partially removed.

According to Fig.-3, it is shown that with an increase in the concentration of sulfuric acid, the current yield of titanium dissolution monotonically increases. When studying the anodic dissolution of titanium by recording the potentiodynamic curves, an increase in the values of the maxima of the titanium dissolution currents was recorded by 1.5 times with an increase in the concentration of hydrogen ions from $1 \mathrm{M}$ to $2 \mathrm{M}$. In the case of AC electrolysis, the increase in the current output within the specified acid concentrations is also 1.5 times.

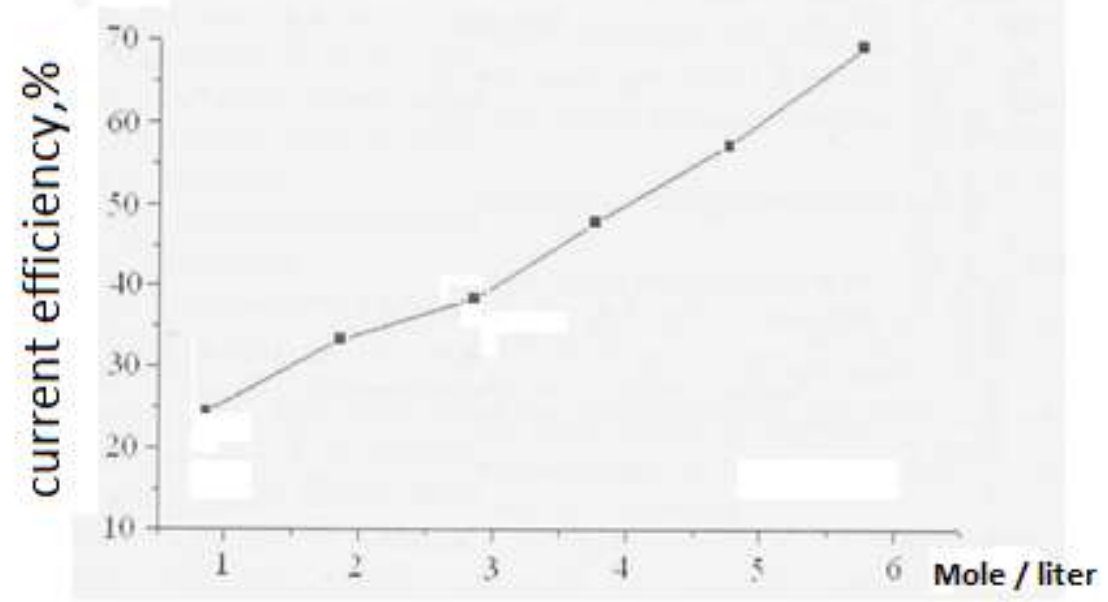

$\mathrm{i}=700 \mathrm{a} / \mathrm{m}^{2} . ; \mathrm{t}=25^{\circ} \mathrm{C} ; \tau=0.5$ hour

Fig.-3: The Influence of the Concentration of Sulfuric Acid on the Current Efficiency of Dissolution of Titanium 
RASĀYAN J. Chem.

Vol. 14 | No. 4 |2720-2727| October- December | 2021

Table- 3 shows the effect of the electrolyte temperature on the current output of titanium dissolution. When the temperature of the electrolyte increases to $60^{\circ} \mathrm{C}$, the current yield of titanium dissolution increases to $49.1 \%$ and does not change further. On the other hand, starting from $60^{\circ} \mathrm{C}$, there is significant evaporation of the electrolyte.

Table-3: Effect of the Electrolyte Temperature on the Current Output of Titanium Dissolution to Form Titanium (III)

\begin{tabular}{c|c|c|c|c|c|c}
\multicolumn{7}{c}{ Sulfate } \\
\hline $\mathrm{T}{ }^{\circ} \mathrm{C}$ & 30 & 40 & 50 & 60 & 70 & 80 \\
\hline Current Performance, $\%$ & 28.3 & 33.6 & 40.4 & 49.1 & 50.3 & 50.5 \\
\hline
\end{tabular}

As a result of the dissolution of titanium in acids, the color of the solution first becomes purple, and in a saturated solution, it changes to green. This confirms that the titanium (III) salts are present in the solution as aqua complexes in the form of hexahydrate $\left[\left(\mathrm{H}_{2} \mathrm{O}\right)_{6}\right]^{3+}$, as shown in some literature. In concentrated solutions of $\mathrm{H}_{2} \mathrm{SO}_{4}$ and NSL, the color of the solution changes from purple to green, as half of the water molecule of this complex compound is converted into sulfate or chlortab. When polarized by alternating current, the dissolution of titanium in sulfuric acid electrolytes, as in the case of a solution of hydrochloric acid, proceeds with the formation of a solution of trivalent titanium sulfate, as evidenced by the purple color of the solution. During electrolysis, titanium sulfate crystals begin to fall out over time. X-ray phase analysis (DRON-4) was used to study a salt sample obtained after electrolysis, and it was found that its composition mainly contains $\mathrm{Ti}_{2}\left(\mathrm{SO}_{4}\right)_{3} * 5 \mathrm{H} 20$, the X-ray image of the sample is shown in Fig.-4.

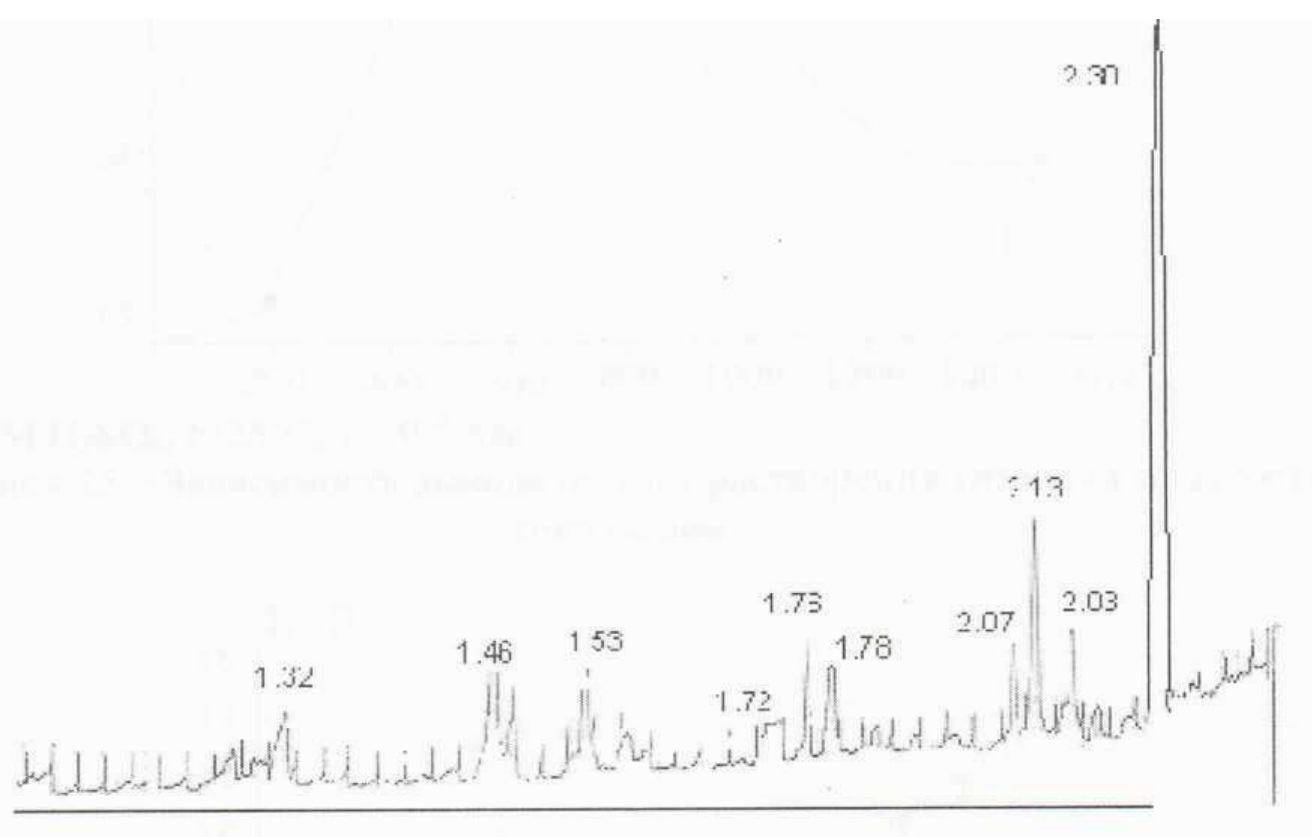

Fig-4: X-ray image of a Sample of Titanium (III) Sulfate Obtained after Electrolysis.

Based on the results of studies of the electrochemical behavior of titanium in sulfuric acid solutions under industrial alternating current polarization, a method for producing tetravalent titanium (III) sulfate was developed, and an innovative patent of the Republic of Kazakhstan was obtained (A method for producing tetravalent titanium sulfate. N22655). Titanium (III) sulfate is the starting material for the production of high-quality white pigments. Currently, titanium (IV) - $\mathrm{Ti}\left(\mathrm{SO}_{4}\right)_{2}$ sulfates is produced in the industry using a complex multi-stage technology.

\section{CONCLUSION}

The mechanism of dissolution of titanium during polarization by industrial alternating current in sulfuric acid solutions has been established. It is shown that the dissolution of titanium occurs in the anode halfcycle of alternating current with the formation of a solution of trivalent titanium sulfate. The efficiency of the process decreases due to the side process of oxygen release, which leads to an increase in the thickness 
of the oxide film and as a result, the voltage on the electrode increases. In the cathode half-cycle of alternating current, hydrogen is released, and the passivation of the electrode surface is partially removed. The influence of the main parameters of electrolysis on the yield of titanium current in sulfuric acid solutions has been studied: acid concentration, current density, electrolyte temperature, alternating current frequency, duration of electrolysis. It was found that the maximum current output of $45.2 \%$ is observed in solution: $49.1 \% \mathrm{~W}$ at an alternating current density of $600-1200 \mathrm{~A} / \mathrm{m} 2$, sulfuric acid concentration of $5 \mathrm{~mol} / 1$, $600 \mathrm{~S}$, current frequency of $50 \mathrm{~Hz}$. In this work, a new electrochemical method for obtaining the polarization of titanium sulfate by the alternating industrial current in an acidic medium has been developed. For the first time, the electrochemical dissolution of titanium metal waste used as a bipolar electrode in acidic solutions of $\mathrm{H}_{2} \mathrm{SO}_{4}$ under polarization by the alternating industrial current is studied, depending on various factors: the density and frequency of the alternating current, the concentration of the electrolyte, etc., and the duration of electrolysis. With increasing acid concentration, the chemical dissolution of titanium increases, so the apparent current yield of titanium dissolution is $\mathrm{MH}_{2} \mathrm{SO}_{4}-70 \%$. Finally, our proposed electrochemical method has the following advantages:

1. The synthesis of trivalent titanium sulfate occurs at room temperature.

2. As a resource for the production of trivalent titanium sulfate, non-expensive material, a scrap of titanium-containing components, as well as titanium metal chips, are used, which significantly reduces the cost of the resulting trivalent titanium sulfate.

3. The dissolution of titanium is carried out by industrial alternating current polarization, the process equipment is simplified.

In addition, the practical significance of this study is expressed in the fact that it will be possible to obtain various compounds from titanium metal waste in the form of scrap, chips, i.e. it becomes possible to create a waste-free technology that allows for a huge economic effect. We note that, considering titanium to be a metal insoluble in acidic aqueous solutions, scientists and technologists have not created methods for obtaining its compounds by dissolving titanium-containing metal waste. At the same time, it is known that there are large accumulations of industrial waste containing titanium, which could be processed into various titanium compounds. In addition, titanium compounds are widely used in a variety of industries: in the field of chemistry and metallurgy, as well as in the national economy. For example, titanium hydroxide (IV) is used as a sorbent, titanium dioxide is used as a pigment for dyes, and trivalent titanium salts are used as reducing agents in chemical processes and as charge carriers in the reduction of hard-to-recover selenium (VI), tellurium (VI) and arsenic (V) anions, as well as in the production of ultrafine copper powders.

\section{REFERENCES}

1. Z.H. Shingisbaeva, G.M. Iztleuov, A.A. Abduova, A.S. Taubayeva, N.K. Zhorabaeva, Izvestiya Vysshikh Uchebnykh Zavedenii, Seriya Teknologiya Tekstil'noi Promyshlennosti, 1(379), 323(2019).

2. O.P. Bayysbay, G.M. Iztleuov, N.E. Botabaev, B.U. Baybatyrova, G.S. Ashirbekova, Izvestiya Vysshikh Uchebnykh Zavedenii, Seriya Teknologiya Tekstil'noi Promyshlennosti, 21(379), 306(2019)

3. S. Yu. Kireev, Yu. P. Perelygin, S. N. Kireeva and M. J. Jaskula, Arabian Journal for Science and Engineering, 46, 454(2020), https://doi.org/110.1007/s13369-020-04786-y

4. A.S. Kolesnikov, I. V. Sergeeva, N. E. Botabaev, A. Zh. Al'zhanova, Kh. A. Ashirbaev, Steel in Translation, 47, 605(2017), https://doi.org/110.3103/S0967091217090078

5. Wang, Hao. International Journal of Electrochemical Science, 56, 9313(2020), https://doi.org/110.20964/2020.09.70

6. A. S. Kolesnikov, Russian Journal of Non-Ferrous Metals, 56,1(2015), https://doi.org/110.3103/S1067821215010113

7. O. Takeda, T. Ouchi and T. H. Okabe, Metallurgical and Materials Transactions B, 51, 1315(2020), https://doi.org/10.1007/s11663-020-01898-6

8. R.L. Fisher: US Patent, 1990, No. 4923531A

9. R.L. Fisher and S. R. Seagle: Proceedings of the 7th World Conference on Titanium (1992)), Vol. 3, F.H. Froes and I. Caplan, eds., The Minerals, Metals \& Materials Society, Pittsburgh, PA, USA, 1993, pp. $2265-72$.

10. H. Miyazaki, Y. Yamakoshi, and Y. Shindo, Materia Japan, 33, 51(1994), (in Japanese). 


\section{RASĀYAN J. Chem.}

Vol. 14 | No. 4 |2720-2727| October- December | 2021

11. S. Takeuchi and O. Watanabe: Journal of The Japan Institute of Metals, 28, 627(1964).

12. T. M. Khudyakova, A. S. Kolesnikov, et al. Refractories Industrial Ceramics, 60, 76(2019) https://doi.org/110.1007/s11148-019-00312-2

13. D. Baehre, A. Ernst, K. Weißhaar, H. Natter, M. Stolpe, Ralf Busch, Procedia CIRP The International Academy for Production Engineering 42, 137(2016), https://doi.org/110.1016/j.procir.2016.02.208

14. Hao Wang, International Journal of Electrochemical Science, 15, 9313(2020), https://doi.org/110.20964/2020.09.70

15. A. B. Bayeshov, et al., News of the National Academy of Sciences of the Republic of Kazakhstan-Series Chemistry and Technology, 6, 96(2018), https://doi.org/110.32014/2018.2518-1491.31

16. A. Mamyrbekova, A. Mamitova, et al., Rasayan Journal of Chemistry, 13(3), 486(2021).

17. Aizhan Mamyrbekova, A.D. Mamitova, M.K. Kassymova, Aigul Mamyrbekova, Zh.E. Daribayev, R.E. Pralieva, M.N. Yermakhanov and G.S. Mutasheva, Rasayan Journal of Chemistry, 13(4), 2332(2020), http://dx.doi.org/10.31788/RJC.2020.1345761

18. A. S. Kolesnikov, V.N. Naraev, M.I. Natorhin, A.A. Saipov and O.G. Kolesnikova, Rasayan Journal of Chemistry, 13(4), 2420(2020), https://doi.org/10.31788/RJC.2020.1346102

[RJC-6532/2021] 